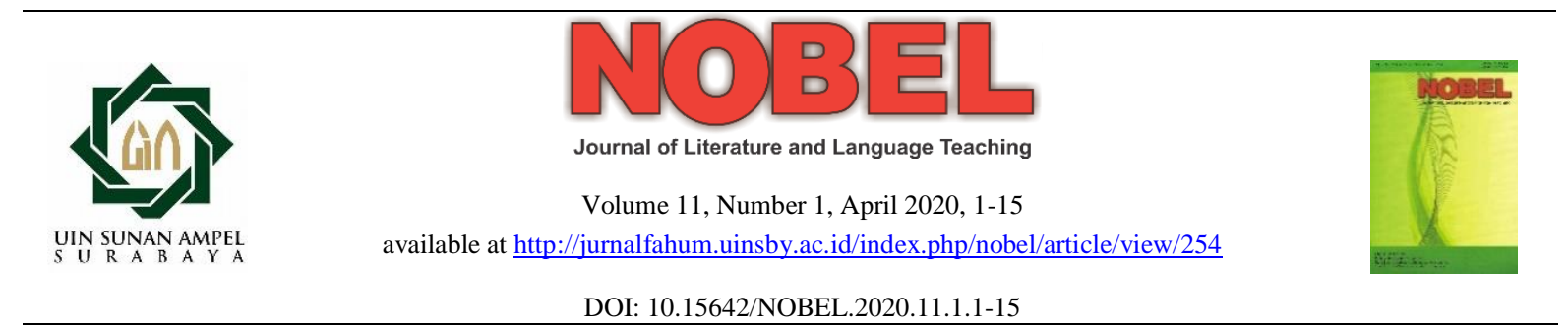

\title{
INTERMEDIAL TRANSFORMATION IN COMIC BOOK MOVIE ADAPTATION OF $X$-MEN: FIRST CLASS
}

\author{
Nur Saktiningrum $\bowtie$ \\ Universitas Gadjah Mada, Jalan Nusantara 1, Bulaksumur Yogyakarta 55281, Indonesia
}

\begin{tabular}{l}
\hline Article Info \\
\hline Article History: \\
Received January 2020 \\
Accepted February 2020 \\
Published April 2020 \\
\hline Keywords: \\
intermedia translation, X- \\
Men: First Class, comic \\
books, movie \\
\hline
\end{tabular}

\begin{abstract}
The objects of this study are eight X-Men: First Class comic books, volume 1 published from September 2006 until April 2007, and X-Men: First Class movie made in 2011. Texts in the forms of dialogues and visual images taken both from the comic books and the movie are the data which are then analyzed qualitatively. Applying intersemiotic translation promoted by Zecca, this study is trying to uncover how social and economic factors influence the translation process and whether there are any continuity and changes along the process. The study focuses on the social and economic aspects involved in the process of transforming X-Men: First Class comic books as the source text into the movie version as the targeted texts. Some adaptation and changes occurred as a consequence; plot and storylines are twisted; characters involved are replaced to meet the expectation of the targeted market of the movie. Supported by those involved in the process and the social issues echoing at the time when the process is happening, the social issues depicted in the texts are also sifted.
\end{abstract}




\section{INTRODUCTION}

At the beginning of the $20^{\text {th }}$ century, there was a new trend within film studies scholarship. Before the $20^{\text {th }}$ century, academic writings on films limited their scope only to the studies related to the technical aspects of cinematic production along with the film producers and directors as the influential factors. Films were beginning to be the objects of critical studies as a work of art when theories pertaining to film had flourished. In this period of development, studies of films had adopted a wider range of approaches that situate cinematic works in multidimensional spatial and temporal contexts. This development had stimulated the growing discussion of more varied aspects of cinema that involves scriptwriting and film historiography.

Today, film studies have reached a vigorous development as an academic discipline following the increasing use of movies as a medium to enhance learnings of history, culture, and society in various extents. The discipline's growth in breadth and depth has also induced studies and discussions on film's relations with other media such as television and literary work, particularly novels. One of the areas of study related to film's intermedial relations that has been gaining critical attention is the intermedial transformation of novel into its movie adaptation. Bluestone (1957), for example, investigates the metamorphosis of six novels into films. His study offers a critical analysis on the limits, the technical aspects, and the capacities of novel and film as a narrative medium and also analytical explorations into major changes that occur in the process when a novel is transformed into a movie.

A brief preliminary observation for the present study has provided a general picture of the current filmmaking industry, which shows the increasingly diverse materials or sources targeted for movie adaptation in terms of intermedial translation of verbal narrative media (novel, comic books, play, etc.) into narrative motion pictures. Hence, not only novel but many other works of art have also been transformed into movies. One of the narrative media which have been frequently targeted for film adaptation is a comic book. One example of comic book movie adaptation is the transformations of X-Men comic books from Marvel Comics into movies with the same titles. There are eight $X$-Men movies to date, all of which have drawn a tremendous response from the public (TMDB, n.d.).

X-Men comics, which are the source materials of X-Men movies, were first published during the 1960s. The comic books were written by Stan Lee and illustrated by Jack Kirby. Until today, there have been hundreds of X-Men comic books published (over 175 titles) with 
different numbers of volumes for each title ranging from one title for one book or a single shot to one title for more than ten issues. These numerous X-Men volumes were the source material of the seven X-Men movies, and their two sequels, whose titles bear no "X-Men" name, have been released so far. These facts have raised several critical questions that the present study seeks to address: based on which volume(s) and which comic series were the $\mathrm{X}$-Men movies made? What processes involved in the intermedial transformations of the XMen comic books as the source texts into their movie versions as the target texts? What changes and consistencies had been involved in the specified process?

\section{REVIEW OF LITERATURE}

\section{Intermedial Transformation Process}

The term transformation referred to in this article is to be construed as a process of formal changes or alterations in a general sense. The formal changes brought up as the focus of analysis here are those that are specifically effected in a translation or adaptation between different media. In that case, the term intermedial transformation is also used in the discussion related to it in this article. Intermedial transformation of comics into films customarily and necessarily creates multifaceted changes or adaptations throughout its process. The challenge of explicating the process of intermedial adaptation is much more than merely about the task of investigating what differences between media may entail in such a process. The attempt to explain it would necessitate looking into differences in the historical, social, economic, and cultural dimensions where the source and the target works of the adaptation are situated in. Regarding X-Men comic book movie adaptation, although both the comic and the movie versions have their setting in American society, the different periods during which the publications of the comic books took place (20062007) and during which the movies based on the books were produced (2011) would certainly play significant roles in how both forms of narrative works were produced. Therefore, those aforementioned factors need to be taken into account when making inquiries into the process of intermedial translation. Inherent in this kind of translation is the aspectual differences between the involving media in terms of their nature, function, and structure. Thus, the scrutiny into the transformation of the source medium into the target medium requires identifications and in-depth descriptions of how those three constitutive aspects are translated between media; what changes and consistencies are formed as a result of such translation process; how the contextual background of different 
temporal settings affects the process and the result of the intermedial transformations; how the socioeconomic background of the different eras of productions of the two media contributes to the process and the result of the transformations. These are the general questions that the study in this article tries to answer.

This article discusses the process and the results of the intermedial transformation of X-Men: First Class. The source texts under study are eight series of X-Men: First Class comic books published in the period between September 2006 and April 2007. The target text of the transformation comprises the movie version of the eight comic series released on 25 May 2011 with the same title. The primary data for the analysis were taken from the textual and pictorial elements of X-Men: First Class comic books and movie that include the printed dialogues, the pictures or visual images, and the movie scripts. As hinted earlier, the scope of discussion in this article is limited to the process and the result of the intermedial transformation in the comic book movie adaptation of X-Men: First Class, particularly as an attempt to identify and explain the changes and/or consistencies that had been generated in the process and the result of translating the intrinsic elements of the source texts into those of the target texts which are largely shaped by the medium (film) which is very much different from that of the source texts (comic book).

The comics and the movie as the focus of discussion in this article were treated as texts (in words and pictures or visual images). These texts served as the material object of the present study and were analyzed and interpreted to build answers for the questions raised earlier. The discussion of the texts was developed based on a theory of intersemiotic translation. Guided by this theory, the printed/ verbal texts in the forms of dialogues in the comic books, the script of the movie, and the visual images in both the comics and the movie were assumed to have meanings. The meanings were drawn through critical interpretations that were intended to lead the discussion to the elucidation of the changes and consistencies that had been brought about in the process of the intermedial translation and the final result of its work.

This study is based on a theory in the framework of intersemiotic translation developed by Federico Zecca. Drawing on the theses and conceptualizations put forward by his predecessors in intersemiotic translation studies such as Jakobson (1959), Marrone (1998) and Dusi (2003), Zecca argues that:

... Thus, today the category of intersemiotic translation is generally used to describe the re-production of a source-text (or part of it) belonging to a source-system (here, 
the comics system) in a target-text (or part of it), which belongs to a target-system (here, the cinematic system).

Further, Zecca explains that translation process is a process of cultural semiotics, and it is a common occurrence. The process includes the transfer and reproduction of each semiotic unit of the source text, in all forms and sizes, in the target text. This notion presupposes that every intertext relation, be it intersemiotic or intrasemiotic, is generated by a translation process which has happened previously in which some elements in a text are transferred to another text. It is these elements that play a major role in building the intertext relation of the two texts.

The perspectives of intersemiotic translation and translation process presented above had provided a theoretical framework for the writer of this study to interpret the visual images in the X-Men: First Class comics and screenshots from the comics' movie version along with their associated dialogues as sign units with certain meanings. Moreover, views concerning the abovementioned theory of intersemiotic translation agree on its applicability to any study of translation involving source and target texts with different semiotic systems and media. The theory's wide scope of the application provides the writer of this article with a strong ground to adopt it as a basis of analysis for the study of $\mathrm{X}$-Men comic-to-movie translation presented here. Its use in this study is expected to unveil the influential factors that largely contribute to the process of the intermedial translation under study as well as to the resulted changes and consistencies of the constitutive elements in the involving texts.

\section{DISCUSSIONS OF MAIN THEMES}

\section{Economic Factor in Intermedial Transformation}

The American youths targeted by the movie marketing for X-Men are those who read superhero comics in their childhood. This is one of the main reasons why the X-Men comic book movie adaptation has been considered a profitable business to undertake for Hollywood. The themes, the characters, and the stories are already familiar to the targeted audience, which means the approximate calculations of the profit would likely be much less speculative. Moreover, it is also highly likely that the products of the involving intermedial transformations (the X-Men movies) would attract the older audience as well. The audience who were in their 40s or 50s when X-Men: First Class was played on cinemas had grown up watching superhero serials on television or reading their comic versions. To them, Superman, Batman, and Spiderman are familiar superhero figures. 
Thus, by the time X-Men: First Class movie was released in cinemas in 2011, many of them would feel nostalgic and would be tempted to watch the movie version of the comics they had enjoyed back in their childhood days while taking their children to the cinema. In this regard, the older audiences, which are those in the age group of over 25 years old, were considered as the bonus profit for the marketing of X-Men: First Class, whose main target audiences were those in the younger age group (under 25 years old).

The market research of movies produced as an intermedial adaptation of comics by Sam Raimi (2002), whose main objects of research were Spiderman movies, reports that Spiderman movies and several other superhero movies had been able to attract audiences across age groups and genders. In the field of movie market research, movies that are appealing to large segments of the audience are regarded as movies that dominate "four quadrants." Geoff Ammer, as cited by Nathalie Dupont (2011), explains that four quadrants refer to the four groups of movie audiences: male and female as gender-based groups and older and younger as age-based groups. A producer who intends to score a box office success with his/her newly produced movie would need to use all resources at his/her disposal to appeal to all four groups of audience specified above. Based on a number of statistic reports (Dupont, 2011), the X-Men film series has always been able to reach the blockbuster level of sales, which amounted to over $\$ 150$ million.

$X$-Men: First Class success can be indicated from its earnings from its opening in cinemas worldwide that reached $\$ 355,408$.305. It was a fantastic total amount of dollars that could only be collected when its sales had managed to take control of the four quadrants of marketing. A huge number of people of all ages, men and women, went to see the movie and therefore gave a great contribution to the movie's commercial success. In sum, X-Men: First Class's achievement is evident not only in its hundreds of millions of dollars worth of revenue collected but also the size and the segments of its audience. Indeed, such a large number of the audience suggests that this movie was popular among all groups of audiences (The Numbers, n.d.).

The extent of X-Men: First Class's popularity had reached beyond the American public. The movie's impressive international box office achievement showcased that it was also immensely popular at the international level. For American readers and audiences, the superpower characters in X-Men series such as Prof. X, Magneto, Mystique, Emma Frost, Beast, Banshee, Azazel, Angel, and many others, are very familiar fictional figures which originated in the USA and have been part of American culture for years. The younger generation of Americans would look up to them as an 
inspirational insight of how the new myths of American superhero were built and grown over time because they did not grow up with the legacy of the older myths that had been developed and disseminated long before their generation was born. As for international audiences across the globe, they could always relate to X-Men fictional figures in some other meaningful ways such as seeing them and their story world as representations of injustice, inequality in citizens' rights, gender inequality, poverty, natural disaster and anti-establishment occurring in their respective home countries since these are some of the issues in reality to which the movie seems to draw the audience's attention. For their young fans, X-Men superheroes are part of their dreams and imaginations about power, justice, capability, and adroitness in coping with various problems in their daily life.

Apparently, the embodiments of many people's dreams and fantasy in X-Men: First Class is one of the reasons why so many audiences were wholeheartedly willing to spend their money to buy tickets and watched the movie in cinemas. Apart from the entertainment the movie had to offer, the young audiences, in particular, were drawn to the movie as they found that for some reason they could identify with the X-Men characters in that the superheroes' struggles in X-Men fictional world were somehow comparable to their own ups and downs in their growing up years into adulthood. Metaphorically, those familiar superheroes represented their wish of winning the battles against numerous social problems that they couldn't always deal with triumphantly in real life. Superheroes in movies have almost always come out as a champion in the end, and it is presumably because of this sense of happy ending that they were eager to invest in superhero movies.

The American film industry has long been perfectly aware of this fact. Therefore, an intermedial adaptation from comics into film is seen as a very profitable filmmaking business to take up. To date, movies made from intermedial adaptation (such as $X$-Men: First Class) are regarded as a production that stands a good chance of creating a blockbuster hit. In this sense, this category of filmmaking (intermedial adaptation) is considered promising in bringing profitable opportunities to filmmakers in the US. Marketing for X-Men: First Class was made easier by the familiarity of the comic books on which the movie was based among the American public, not to mention the fact that it already had far-reaching fan communities throughout the US. In comic-to-movie adaptation business, fanbase advantage can turn into a two-edged sword in that if the filmmakers fail to manage it, it will cause them a negative film promotion for the movie distribution. In X-Men: First Class case, however, its contributing filmmakers were 
proven capable of managing the preceding popularity of its comic version as a leverage to attract a large number of audiences who were mostly X-Men fans by adapting it into a movie version with a high production value to their satisfaction. In turn, their satisfaction greatly boosted the movie's ticket sales.

Realizing that the fans of comic books based on which some promising movies were made play a very important role, Hollywood makes it necessary to organize an event that presents comic-based movies and targets comic fans as its intended audiences to their advantage. Producers and directors of upcoming movies usually attend the convention to release the movies' trailers. For example, a convention called Comic-Convention 2017: The X-Men are 'Gone' in New Series The Gifted was held on 21 July 2017 where fans of X-Men comics (the source texts of intermedial adaptation) were presented with the preview of what to expect from the newly produced X-Men TV series (the target texts of adaptation) (Collura, 2017). In its development, events such as Comic Convention are increasingly significant in their contribution to the marketing of movies made from intermedial adaptation. Because of this fact, Hollywood decided to hold it on a regular basis as a compulsory part of their marketing strategies.

Furthermore, the sponsors' role in the productions of movies of this category generally proves to be a great contribution as their financial resources. Superman II, for instance, received $\$ 42,000$ in funding from featuring the Marlboro logo and cigarettes in it (Lester, 1980). Batman Begins dan The Dark Knight benefited from Lamborghini in the same manner as Superman II from Marlboro, although not as much. Lamborghini cars were featured in the movie in exchange for a great amount of funding for its production. In addition to such sponsorship, there is also a kind of business contract based on which certain characters, titles, or actors of the released movie are used to promote a product. Reebok had used Spiderman's character to promote its products by highlighting the superhero wearing Reebok shoes. Unlike Superman and Spiderman film productions, $X$ Men: First Class production was not supported by many big sponsorship contracts. Though there were several products featured in the movie, they did not amount to a significant contribution to the movie's production.

While not relying much on sponsorship, X-Men: First Class gained appreciation from other sectors. Producers and manufacturers of children's toys were interested in creating products based on superhero characters in X-Men that have been children's idols for a long time. They made and sold action figures of those familiar superheroes, and for this business opportunity, they had to pay a huge amount of royalty. The movie's revenue 
from contracts with children's toy businesses proved substantial. The rapid development of technology in the entertainment industry was another sector X-Men movies had benefited from. There have been numerous video games that were made based on X-Men mutants. Between 1993 and 2014, there were at least 23 video games created with " $\mathrm{X}$ Men" in their titles. There were still other games that used one of X-Men mutant characters in their designs, such as Wolverine (5 titles). Those products, toys and video games were advertised in several media during the same period when X-Men movies were released and distributed to cinemas. This is an effective marketing strategy for those movies. Even the publisher of X-Men comic books found that the advertisements of those products had helped them with their own publicity.

Although not all film studios in Hollywood produce movies based on comics, the amount of profit some filmmakers have succeeded in accumulating from this segment of film production has made Hollywood producers take it into serious consideration as a promising business option. As informed by Stephen Norrington (1998), Blade, albeit a less popular superhero character in comic books than Superman and Spiderman, did well in generating large profit. With a production budget of $\$ 45$ million, the movie made a net profit of $\$ 70$ million (Kaye, 2018). X-Men: First Class, which was produced on $\$ 160,000,000$ million budget, had made $\$ 355,408,305$ profit to date (The Numbers, n.d.)

\section{Social Dynamics in Movies Made from Intermedial Adaptation Process}

Indeed, the worlds described in X-Men: First Class comics and movie are imaginary story worlds which will never exist in reality. Still, certainly, a work of literature or art couldn't possibly be created in a vacuum and without contexts. A related question about this axiom in studying any work of literature would be which social context(s) brought about or inspired its creation? Does the social context reflected in the comic version of $X$ Men: First Class correspond with the social context reflected in its movie version? Do the superheroes in both versions of $\mathrm{X}$-Men narrative represent certain groups of society, certain social conditions and/or values, and also some expectations of certain members of society with whom both versions were associated?

For the purpose of making an in-depth comparison of the two versions of $X$-Men: First Class narrative (comics as the source text and movie as the target text), the mutant characters are considered the most conspicuous indicator to begin with. In the comic version, Prof.Charles Xavier (Prof. X) is presented as the central character, just as it is in the movie version. Both versions of the narrative also present him with the role of 
educating young mutants at a private school he had specifically founded for their kind, Xavier's School for Gifted Youngsters. The names of these mutant youngsters are Cyclops, Marvel Girl, Beast, Angel, and Iceman. Each of them was born with X-factor genes that had given them a special gift or superpower: Cyclops has eyes that can shoot fire, Beast has an incredible physical strength of a gorilla or great ape, Angel can fly, Iceman can create and control ice, and Marvel Girl has telekinetic power that is similar to Prof. Xavier's. In the eight series of X-Men: First Class comic books, under Prof. X's command, these mutant heroes fight against evil mutants. In the series' movie adaptation, Prof. X trains a group of these following gifted students: Raven/Mystique; Beast; Havok, a mutant with the superpower of absorbing others' energy and using it to her advantage; Banshee, a mutant with the power of producing ultrasonic wave and flying; Darwin, a mutant with the power of changing his shape to adapt to his environment and needs; and Angel Salvadore, a mutant who has wings like a dragonfly's.
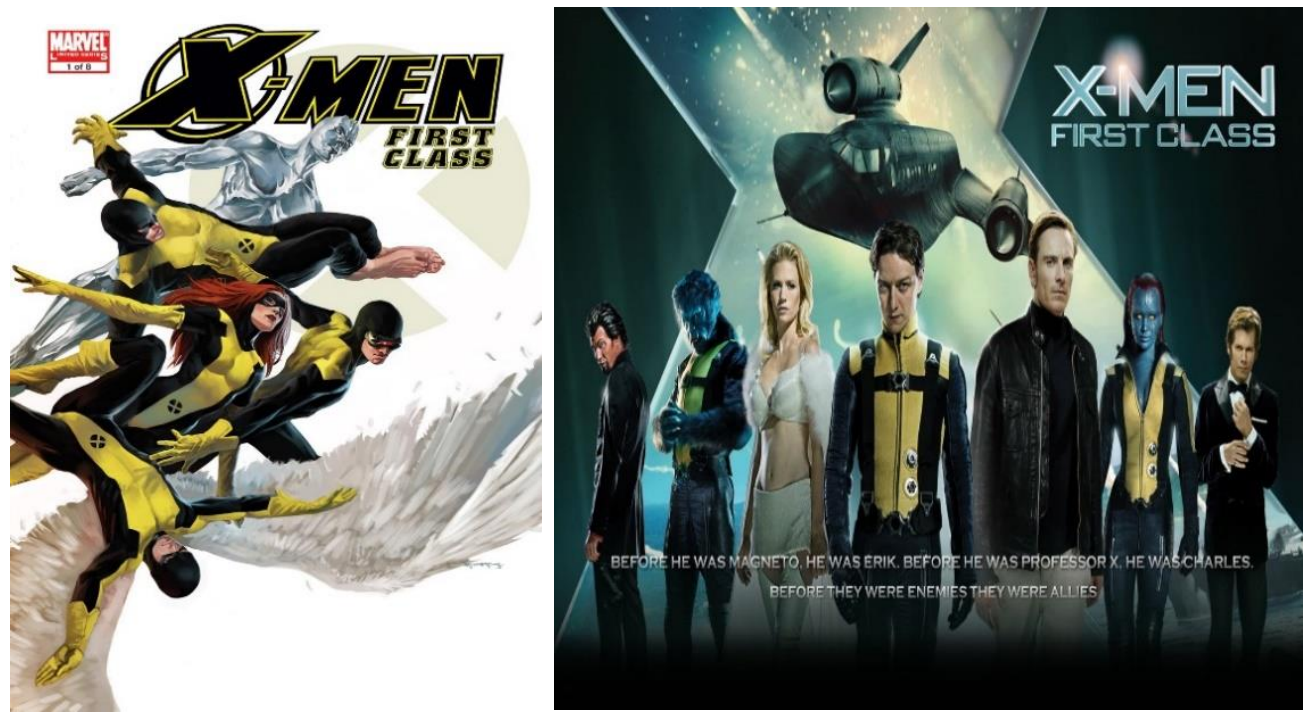

Picture 1: X-Men: First Class Series Cover for Issue 1 dan X-Men: First Class 2011 Movie Poster

Those differences in mutant characters can be associated with the fact that four mutant students of Prof. $\mathrm{X}$ in the comic version had appeared in the previous three X-Men movies. If the four characters were once again featured in X-Men: First Class movie with 1960s setting, their presence would have been out of place. There is also an adjustment to a mutant character named Banshee for some reason. In the comic version, this mutant is narrated as an adult woman coming from Ireland, while in the movie version, Banshee is an American young man. 
Moreover, X-Men fans were offered with a climax in the movie that did not happen in the comic version. The loyal readers of X-Men comic books have long been familiar with the story that the enmity between Prof. X, the good mutant leader, and Magneto, the evil mutant leader, is caused by the increasing disagreements on what they are supposed to believe and what values they need to uphold. In the movie version, their hostility is presented as an unresolved drama escalating into a tragic consequence. The two influential mutants from the good side and evil side were initially two best friends who fight together against people who are determined to exterminate mutants from the earth. Over time, they eventually took different approaches in dealing with their opponents and went on separate ways after a prolonged conflict. The changes in events related to Prof. X and Magneto's conflict and hostility made by the producers of the movie can be regarded as an attempt to bring a certain social issue into attention.

The social and historical contexts of X-Men: First Class movie can be associated with the temporal setting of the story it narrates. In this target text, the setting of the story characterizes the condition of American society in 1962. The atmosphere of this period is dominated by the conflict crisis between the US and Cuba and the Cold War between the US and the Soviet Union. Prof. X and Magneto's alliance is narrated as a collaborative power to protect the U.S. national interest from Soviet Union's government, a heroic narration with nationalism overtone that is frequently found in various American superhero narratives. However, this vantage point could not be found in the comic version. The comic books of X-Men: First Class were published from 2006 to 2007. They feature stories of how Prof. X's students engage in battles with antagonistic mutants or monsters with a superpower from the dark side. These mutant opponents are complex characters. Some of them cause destruction for the reason of self-defense such as Kongklomerat, as narrated in X-Men: First Class vol. 1, issue 1. Some others were once humans before they turned into mutants because of lab accidents, as narrated in vol. 1, issue 2.

Despite the differences between the source and the target texts in terms of the characterizations of the opponent characters, both versions are parallel in part of the story of X-men mutants fighting against opponents who are other than themselves; the part that represents how a society should resist injustice in any way possible to re-establish the society's stability and prosperity. One example is the part in which the mutants fight against Kongklomerat in the freezing North Kutun. When the mutants find out the reason behind the monster's destructive behavior, they demand that humans should stop their 
explorations that have been threatening Kongklomerat's survival. The mutant heroes believe that if the threat is lifted, Kongklomerat would be back to its peaceful life while waiting for the end of its life cycle.

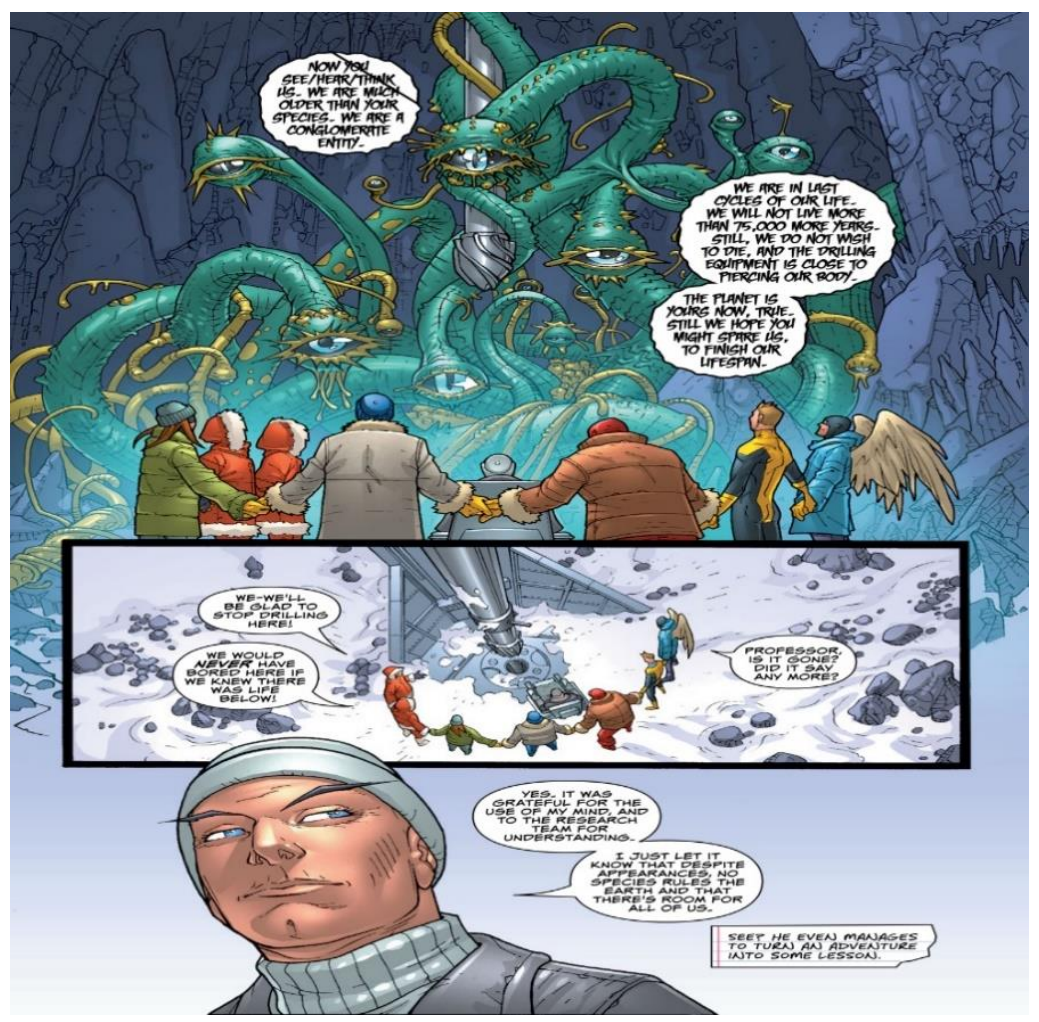

\section{Picture 2: X-Men: First Class Comic Book Volume 1 Issue 1}

As a social group, X-Men can be construed as a community whose members have distinctive traits or characteristics that distinguish them from the members of other communities in their vicinity. Their superpower is the main reason for them to create their own group and feel comfortable to survive and work together under Prof. X's leadership and guidance. Prof. $\mathrm{X}$ is the one who completely understands how hard it is to live in a society that hasn't been able to welcome the mutants' presence among them wholly. Their special gifts as mutants become a great challenge because they live in a society that disapproves or rejects them because of that different trait. They are endowed with a superpower that they can use for the benefit of humankind, but this gift puts them in a very difficult position that makes them unable to fit in among the majority. The pressure of society's disapproval has motivated some of the mutants to keep their power a secret among ordinary people or even to remove it altogether (e.g., Beast in X-Men: First Class) so that they can blend in with the majority and completely fit in among them. 
The social issue related to the 'unfortunate' difference experienced by the X-Men mutants can be interpreted as a representation of the complexity of social difference and the challenge of being unfavorably different among the majority that the producers wish to communicate the audiences of the movie. Both in the source and target texts of $X-M e n$ : First Class, the gifted youngsters (mutants) can be understood as a community that represents minority group(s). In fact, minority issues are a noticeable aspect of both the comic book and the movie versions. The follow-up question will be which minority group that the X-Men mutant characters represent? This question can be answered through several perspectives. The answers might imply the complication of social problems in reality that comprises the tensions between individual identity and otherness, between minority and majority and between discrimination and marginalization.

In the source text, the X-Men community can be interpreted as a representation of minority groups in the U.S. They are different from the majority who are generally characterized as white, Anglo-Saxon, Protestant, and male. The implication is that the problematic difference concerns the issues of race, gender, and economic status. The struggle of the X-Men characters can be juxtaposed or associated with the Civil Rights Movement in the U.S.A. In his interview with The Guardian, Lee said that he purposefully crafted the team to reflect the civil rights race movement of the $60 \mathrm{~s}$ :

"It occurred to me that instead of [the X-Men] just being heroes that everybody admired, what if I made other people fear and suspect and actually hate them because they were different? I loved that idea; it not only made them different, but it was a good metaphor for what was happening with the civil rights movement in the country at that time." (Strauss, 2000)

The mutants have to go through the pressure of having to behave acceptably among the crowd by socializing with their own group, hiding their power, making physical adaptation when they need to interact with non-mutant people, among others. For example, Cyclops has to constantly wear special glasses to cover his eyes, and Angel has to hide his wings by covering them with particular clothes. These strategies can be seen as an attempt to negotiate on the minority's part to adapt themselves to the society where they live. They are required to control their power/gift and hide any physical mark that makes them visibly different from ordinary people by any means possible. Thus, it is made necessary for them to look normal and acceptable in society. 
In the target text, X-Men characters can be interpreted as a representation of LGBT community which is one of minority groups in the U.S. By putting them in the context of the period of time when the movie was released, 2011, and taking into account the statements made by the people who participated in the production process of the movie; the above interpretation can be considered defensible. Zack Stentz, the movie screenwriter, commented on Facebook (Quoted by Polo, 2011) in response to people's denial of LGBT issues: "Um, no offense, but you're wrong. I helped write the movie, and can tell you the gay rights/post-holocaust Jewish identity/ civil rights allegory stuff was all put there on purpose."

Zack was not the only gay who got involved in the production of X-Men: First Class movie. Zack and other gay contributors in the production of the movie gave their ideas about the scenes and ideology that can represent the LGBT group. Hank's wish to discover a cure that can take him back to normal in the movie reflects the concern of the members of the LGBT community as they realize that their sexual orientation deviates from what is considered 'normal' by the standard of the society where they live.

\section{CONCLUSION}

X-Men: First Class movie (2011) was produced through an intermedial transformation of the comic books with the same title $(2006$ - 2007) as the source text. Although both narrative versions use the same title, they differ in their temporal setting, plot, and characterization. Not only the plot in the target text is significantly different from that in the source text, but the characters featured in both versions also are not identical. Although there are a number of characters from the source text featured in the target text, changes are made to their roles, origins, and presence in the story. These major changes had split the fans of X-Men comics, who had been a loyal reader since 1963, into two groups: those who thought that some changes and adaptations are inevitable in transforming the comic version into the movie version, and those who responded negatively to those changes.

For those who saw those changes as a downside, the changes of the important elements made to the comic books had 'disrupted' their framework of interpretation and horizon of expectation they had been maintained for years as the loyal readers of X-Men comic books. However, the fact that X-Men: First Class movie had succeeded in gaining a huge amount of profit and securing its position as a blockbuster movie is an undeniable indication that this movie was widely accepted in both national and international levels. 
For many of its audiences, this movie about mutant superheroes could play a role as a conduit to communicate so many questions they have wanted to ask. Various minority groups felt represented by the characters in the movie that were not present in the comic version. These changes in the process of adaptation are inevitable or even necessary since there are differences in the periods between the publications of X-Men: First Class comic books and the release of its movie version as well as differences in interests and perspectives among the filmmakers who had taken part in the process of comic/movie intermedial adaptation during the production. All things considered, all changes and consistencies that the filmmakers have decided to create in transforming elements of the source text into the elements of the target text in the process of comic book movie adaptation are a logical consequence in performing such intermedial translation of narrative texts. There will always be many factors that are external to the texts, such as ideological and economic contexts of their production.

\section{REFERENCES}

Bluestone, G. (1957). Novel into film: A critical study. Baltimore: The John Hopkins Press.

TMDB. (n.d.). X-Men collection. Themoviedb. Retrieved November 6, 2017. https://www.themoviedb.org/collection/748-X-men-collection.

Collura, S. (2017, July 22). Comic-Con 2017: The X-Men are 'gone' in new series The Gifted. IGN. www.ign.com/articles/2017/07/21/comic-con-2017-the-X-men-are-gone-in-newseries-the-gifted

Dupont, N. (2011). Hollywood adaptations of comic books in a post-9/11 context: the economic and cultural factors. Transatlantica, (2), 1-21. http://journals.openedition.org/transatlantica/5419

Kaye, B. (2018, August 29). 20 years ago, blade made comic book movies credible: A serious approach to high-concept comics paved the way for the modern superhero film. Consequence of Sound. https://consequenceofsound.net/2018/08/20-years-ago-blademade-comic-book-movies-credible/

Polo, S. (2011, June 11). X-Men: First Class screenwriter confirms LGBT subtext as totally intentional. The Mary Sue. https://www.themarysue.com/x-men-first-class-gay-subtext/

Strauss, B. (2000, August 12). Generator X: An interview with Stan Lee. The Guardian. https://www.theguardian.com/film/2000/aug/12/features

The Numbers. (n.d.). X-Men: First Class (2011). The numbers where the data and the movie business meet. Retrieved November 19, 2017 at 01:05 from www.thenumbers.com/movie/X-Men-First-Class

Zecca, F. (n.d.). Comics in motion: The intersemiotic translation of comics into film. Retrieved March 19, 2017 from http://www.academia.edu/10100816/Comics_in_motion_The_intersemiotic_translation_ of_comics_into_film_draft_ 